\title{
Yelisman Zebua ${ }^{1}$
}

\section{KESIAPAN PELAKSANAAN PRAKTIK KERJA INDUSTRI PROGRAM STUDI PENDIDIKAN TEKNIK BANGUNAN IKIP GUNUNGSITOLI}

\begin{abstract}
Abstrak
Penelitian ini bertujuan untuk mengungkapkan tentang kesiapan mahasiswa Pendidikan Teknik Bangunan IKIP Gunungsitoli semester genap TA 2020/2021. Metode penelitian deskriptif kuantitatif dengan populasi mahasiswa semester VIII Teknik Bangunan IKIP Gunungsitoli yang melaksanakan Praktik Kerja Industri (PKI) TA 2020/2021. Sampel dalam penelitian ini sebanyak 33 orang mahasiswa dengan pengambilan sampel menggunakan total sampling. Data dikumpulkan menggunakan angket, dengan 5 kategori kesiapan mulai dari: tidak siap, kurang siap, cukup siap, siap, sangat siap. Hasil penelitian, didapatkan data kesiapan mahasiswa Jurusan Teknik Bangunan IKIP Gunungsitoli dalam melaksanakan PKI berada pada kategori siap untuk aspek afektif, aspek kognitif dan psikomotor. Dilihat dari aspek secara keseluruhan bahwa kesiapan praktek kerja industri mahasiswa Teknik Bangunan IKIP Gunungsitoli dalam melaksanakan PKI di Kota Gunungsitoli berada pada kategori siap.
\end{abstract}

Kata Kunci: Praktik Kerja Industri, Kesiapan, Program Studi Teknik Bangunan

\begin{abstract}
The goal of this research is to determine the readiness of Building Engineering majors at IKIP Gunungsitoli in the even semester of the 2020/2021 academic year. For the 2020/2021 academic year, we used a quantitative descriptive study approach with a population of IKIP Gunungsitoli Building Engineering students who participate in Industrial Work Practices (PKI). The sample size for this study was 33 students, and total sampling was used. A questionnaire was used to collect data, with five levels of readiness: not ready, less ready, quite ready, ready, and very ready. The study's findings revealed that students from IKIP Gunungsitoli's Department of Building Engineering are ready to implement PKI in the ready category for affective, cognitive, and psychomotor elements. The readiness of field practice for students of IKIP Gunungsitoli Building Engineering in implementing the PKI in Gunungsitoli City is in the ready category, based on the overall picture.
\end{abstract}

Keywords: Industrial Job Experience, Readiness, And Study Program In Building Engineering

\section{PENDAHULUAN}

Di era globalisasi ini bangsa Indonesia diharapkan mampu mencetak sumber daya manusia (SDM) yang berkualitas, dikarenakan persaingan di dunia kerja semakin ketat. SDM yang dikatakan berkualitas salah satunya adalah terbentuknya tenaga kerja profesional yang terampil dan ahli dalam bidangnya. Keterampilan dan keahlian seorang tenaga kerja dapat di peroleh melalui pembelajaran di instansi pendidikan atau melalui pelatihan keterampilan di lembaga pelatihan keterampilan. Dalam rangka menyiapkan SDM yang relevan dengan

\footnotetext{
${ }^{1}$ Prodi Pendidikan Teknik Bangunan, IKIP Gunungsitoli

Email: yelyszeb@gmail.com
} 
kebutuhan dunia kerja, Perguruan tinggi (Perti) merupakan wahana penyelenggara program pendidikan dan pelatihan bagi mahasiswa. Kegiatan belajar mengajar pada tingkat Perti diarahkan untuk membentuk kemampuan mahasiswa dalam mengembangkan perolehan belajarnya baik pada aspek pengetahuan, keterampilan dan tata nilai maupun pada aspek sikap guna menunjang pengembangan potensinya. Perti diharapkan mampu mencetak SDM yang siap pakai di dunia kerja.

Guna memenuhi tuntutan keterampilan-keterampilan yang dibutuhkan oleh dunia kerja, Prodi Pendidikan Teknik Bangunan (PTB) IKIP Gunungsitoli menyelenggarakan program pembelajaran praktik kerja industri di dunia kerja secara langsung. Program praktek kerja industri bertujuan agar mahasiswa memperoleh pengalaman langsung bekerja di industri yang sesungguhnya. Menurut Hamalik (2005) praktik kerja industri atau di beberapa sekolah disebut On The Job Training (OJT) merupakan modal pelatihan yang bertujuan untuk memberikan kecakapan yang diperlukan dalam pekerjaan-pekerjaan tertentu sesuai dengan tuntutan kemampuan bagi pekerjaan.

PKI pada dasarnya merupakan bentuk pendidikan yang melibatkan mahasiswa langsung bekerja di DU/DI agar nantinya mahasiswa memiliki kemampuan atau kompetensi yang sesuai dengan harapan dan tuntutan DU/DI, serta memperoleh pengalaman kerja sebagai salah satu hal untuk meningkatkan keahlian professional. Hal ini cukup beralasan mengingat DU/DI memerlukan tenaga kerja yang berkualitas, professional di bidangnya untuk mengoperasikan peralatan yang semakin canggih sebagai dampak dari perkembangan teknologi. Dalam melaksanakan PKI dibutuhkan kesiapan berupa kompetensi mahasiswa yang mengarah pada kebutuhan dunia kerja/industri seperti penguasaan pengetahuan (kognitif), sikap (afektif) dan keterampilan (psikomotor). Dengan adanya kesiapan, maka diharapkan suatu pekerjaan dapat dilaksanakan dengan efektif dan bermanfaat sesuai dengan hasil yang diharapkan (Fajra, dkk., 2020, Mallisza, dkk., 2020, Sarumaha. dkk., 2018).

Kesiapan adalah modal utama bagi seseorang untuk melakukan pekerjaan agar mendapatkan hasil yang maksimal. Kesiapan merupakan suatu kondisi psikologis seseorang yang harus ada dalam melaksanakan suatu tugas atau pekerjaan untuk mencapai tujuan tertentu. Kesiapan adalah keadaan siap untuk menanggapi atau tingkat perkembangan dari kematangan yang menguntungkan untuk mempraktekkan sesuatu (Nur, 2017; Zebua, 2020). Kesiapan adalah keseluruhan kondisi seseorang yang membuatnya siap untuk memberi respon atau jawaban dengan cara tertentu terhadap suatu situasi. Kesiapan adalah tingkatan atau keadaan yang harus dicapai dalam proses perkembangan perorangan sebelum dia dapat melakukan sebagaimana mestinya pada bermacam-macam tingkat pertumbuhan mental, fisik, sosial dan emosional. Kesiapan atau readiness adalah persyaratan untuk belajar berikutnya. Kesiapan adalah kesediaan seseorang untuk berbuat sesuatu (Timor, dkk., 2020; Zagoto, 2018,; Zagoto \&Dakhi, 2018). Sedangkan Cronbach mengemukakan readiness sebagai sifat atau kekuatan yang membuat seseorang dapat bereaksi dengan cara tertentu. Kesiapan adalah suatu titik kematangan untuk dapat menerima dan memperhatikan tingkah laku tertentu.

Kesiapan yaitu suatu ungkapan kualitas Sumber Daya Manusia (SDM) yang terbentuk dengan menyatunya 3 ranah (domain) terdiri: Ranah pengetahuan (domain kognitif), Ranah Keterampilan (domain Psikomotorik), dan Ranah Sikap Perilaku (domain Afektif). Sebelum masa titik kematangan dilewati, tingkah laku tersebut tidak dapat dimiliki walaupun melalui latihan yang intensif dan bermutu. Seseorang baru dapat melakukan sesuatu apabila di dalam dirinya sudah terdapat kesiapan untuk mengerjakannya sesuai dengan kenyataan adanya karakteristik individu maka pola pembentukan kesiapan berbeda-beda pula didalam diri masingmasing individu. Berdasarkan beberapa pengertian kesiapan menurut para ahli, dapat disimpulkan bahwa kesiapan adalah keseluruhan kondisi seseorang untuk menanggapi dan mempraktekkan suatu kegiatan tertentu yang memuat aspek mental, keterampilan dan sikap. Aspek tersebut harus dimiliki serta dipersiapkan agar pekerjaan apapun akan memperoleh hasil yang baik. Untuk mengetahui kesiapan seseorang dapat dipengaruhi dari aspek pengetahuan(kognitif), aspek sikap (afektif) dan aspek keterampilan (psikomotor) (Zagoto, dkk., 2019; Zebua, 2018). 
Praktek industri lebih dikenal istilah pemagangan diartikan sebagai bagian dari sistem pelatihan kerja yang diselenggarakan secara terpadu antara pelatihan di lembaga pelatihan dengan bekerja secara langsung di bawah bimbingan dan pengawasan instruktur atau pekerja yang lebih berpengalaman, dalam proses produksi barang dan jasa di perusahaan, dalam rangka menguasai keterampilan atau keahlian tertentu (Gohae, 2020; Dakhi, dkk., 2020). PKI ialah salah satu kegiatan intrakurikuler dalam kelompok mata kuliah bidang studi jenjang program Pendidikan Teknik Bangunan di IKIP Gunungsitoli. PKI merupakan sebuah program strategis yang berfungsi untuk mengetahui lebih jelas aplikasi mata kuliah dalam dunia industri melaui interaksi langsung antara dunia kerja, proses produksi, dan budaya kerja dalam waktu yang ditentukan. Jadi, PKI merupakan suatu program praktek yang dilakukan di dunia usaha atau dunia industri untuk mengaplikasikan pengetahuan teori berdasarkan fakta yang ada di perusahaan/industri serta memiliki konsep tersendiri dalam pelaksanaannya dengan meningkatkan kualitas kerja mahasiswa.

PKI bertujuan untuk meningkatkan pengetahuan, keterampilan, dan sikap mahasiswa di bidang teknologi/kejuruan melalui keterlibatan langsung dalam berbagai kegiatan industri kontruksi. Pelaksanaan PKI bertujuan untuk mendapatkan/menggali pengetahuan praktis di lapangan/ industry melalui keterlibatan langsung dalam berbagai kegiatan di dunia usaha/industri, memupuk sikap dan etos kerja mahasiswa sebagai calon tenaga kerja profesional yang siap kerja, serta mampu membahas suatu topik yang ditemui di lapangan melalui metoda analisis ilmiah ke dalam bentuk suatu laporan Praktek Kerja Industri (PKI). Pencapaian tujuan praktek industri mengacu pada pembentukan profesionalisme dalam bidang keteknikan dan kejuruan yang mencakup wawasan pengetahuan, keterampilan dan sikap yang perlu dimiliki oleh guru maupun teknisi sehingga lulusan akan mampu mengolah pengetahuan dan keterampilan yang dimilikinya menjadi bahan ajar yang bisa memberi pengalaman bermakna bagi mahasiswa yang diajarnya, atau teknisi yang kompeten di bidang studinya. Jadi dapat disimpulkan bahwa praktek kerja industri bertujuan untuk menghasilkan lulusan yang memiliki pengetahuan, keterampilan serta etos kerja yang sesuai dengan tuntutan dunia kerja sehingga memiliki kesiapan kerja yang tinggi (Sugianto \& Suyitno, 2018).

\section{METODE PENELITIAN}

Jenis penelitian ini adalah deskriptif kuantitatif. Populasi dalam penelitian adalah populasi mahasiswa semester 8 Pendidikan Teknik Bangunan IKIP Gunungsitoli yang melaksanakan Praktik Kerja Industri (PKI) TA 2020/2021. Sampel dalam penelitian ini sebanyak 33 orang mahasiswa dengan pengambilan sampel menggunakan total sampling. Data dikumpulkan menggunakan angket. Jenis data dalam penelitian ini data primer diperoleh dari lembaran angket pengetahuan, sikap dan keterampilan pada saat melaksanakan penelitian (mengukur kesiapan kognitif, afektif dan psikomotor). Analisis data yang digunakan yaitu verifikasi data dan analisis deskriptif. Verifikasi dilakukan setelah angket disebarkan kepada responden dan dilakukan pemeriksaan. Anlisis deskriptif dengan menggunakan persentase perindikator yang selanjutnya dikonsultasikan berdasarkan norma kategori kesiapan:

$$
\begin{array}{ll}
X \leq(\mu-1,5 \sigma) & \text { Kategori Tidak Siap } \\
(\mu-1,5 \sigma)<X \leq(\mu-0,5 \sigma) & \text { Kategori Kurang Siap } \\
(\mu-0,5 \sigma)<X \leq(\mu+0,5 \sigma) & \text { Kategori Cukup Siap } \\
(\mu+0,5 \sigma)<X \leq(\mu+1,5 \sigma) & \text { Kategori Siap } \\
(\mu+1,5 \sigma)<X & \text { Kategori Sangat Siap } \\
\text { Keterangan: } & \\
X=\text { Jumlah skor yang diperoleh } & \\
\mu=\text { mean teoritik } & \\
\sigma=\text { satuan deviasi standar populasi }
\end{array}
$$$$
\text { Kategori Kurang Siap }
$$$$
\text { Kategori Siap }
$$ 


\section{HASIL DAN PEMBAHASAN}

Penelitian ini bertujuan untuk mengetahui bagaimana Kesiapan PKI Mahasiswa Pendidikan Teknik Bangunan IKIP Gunungsitoli di Dunia Industri/Dunia Usaha (DU/DI). Berdasarkan tujuan dan data yang telah dikumpulkan, hasil dianalisis dengan menggunakan program SPSS versi 17. Kemudian dilakukan pembahasan tentang kesiapan praktek lapangan industri mahasiswa. Adapun hasil analisis data pada penelitian ini adalah sebagai berikut:

1. Jika dilihat dari kesiapan kognitif, persentase tertinggi kesiapan mahasiswa PTB terhadap PKI berada pada kategori siap $(82,49 \%)$, sisanya berada pada kategori cukup $(2,57 \%)$, dan kategori sangat siap $(14,94 \%)$.

2. Jika dilihat dari kesiapan afektif, persentase tertinggi kesiapan mahasiswa PTB terhadap PKI berdasarkan berada pada kategori siap $(54,68 \%)$, sisanya berada pada kategori cukup $(10,93 \%)$, dan kategori sangat siap $(34,39 \%)$.

3. Jika dilihat dari kesiapan psikomotor, persentase tertinggi kesiapan mahasiswa PTB terhadap PKI berada pada kategori siap (55,91 \%), sisanya berada pada kategori kurang $(2,84 \%)$, kategori cukup $(10,76 \%)$, dan kategori sangat siap $(30,49 \%)$.

Hasil penelitian menunjukkan bahwa kesiapan sebagian besar mahasiswa PTB IKIP Gunungsitoli melaksanakan praktik kerja industri sangat baik. Kesiapan yang baik ditinjau dari segi kognitif, afektif maupun psikomotor. Praktik kerja industri merupakan bagian dari kegiatan yang wajib diikuti oleh mahasiswa PTB IKIP Gunungsitoli, hal ini sesuai dengan kebijakan link and match sebagai upaya pendekatan dunia pendidikan terhadap dunia kerja atau dunia industri dengan metode mengefektifkan sistem keterkaitan kesepadanan lulusan lembaga pendidikan di lapangan kerja, maka sistem link and match merupakan pilihan yang paling strategis, karena sistem ini memberi kesempatan mahasiswa untuk beradaptasi dengan dunia kerja atau dunia industri sehingga setelah mereka lulus akan memiliki kesiapan lebih memadai untuk terjun ke lapangan kerja. Bekal pengetahuan dan ketrampilan kejuruan yang diterima oleh para mahasiswa juga dilengkapi dengan pengetahuan tentang dunia kerja melalui proses bimbingan karir pada saat Praktik Kerja Industri (PKI) yang dibimbing oleh dosen pembimbing dan pembimbing dari industri dimana mahasiswa melaksanakan PKI. Melalui kegiatan tersebut, mahasiswa diharapkan memiliki keterampilan, kesiapan kerja sehingga setelah mereka nantinya dapat terjun langsung ke dunia kerja sesuai dengan bidang keahliannya.

\section{SIMPULAN}

Berdasarkan hasil penelitian dan pembahasan yang telah dilakukan, maka dapat diambil kesimpulan bahwa Kesiapan Praktek Lapangan Industri Mahasiswa semester VIII Pendidikan Teknik Bangunan Dunia Usaha/Dunia Industri (DU/DI) yang melaksanakan PKI TA 2020/2021 dalam melaksanakan Pengalaman Lapangan Industri yang ditinjau dari aspek kognitif, aspek afektif, dan aspek psikomotor berada pada kategori siap. Aspek tersebut harus dimiliki serta dipersiapkan agar pekerjaan apapun akan memperoleh hasil yang baik.

\section{DAFTAR PUSTAKA}

Nur, S. A. (2017). Pengaruh Praktik Kerja Industri dan Motivasi Kerja Terhadap Kesiapan Kerja Siswa Kelas XII SMK Negeri 2 Tenggarong Tahun Ajaran 2016/2017. PSIKOBORNEO, 5(3), 465-476.

Dakhi, O., Jama, J., Irfan, D., Ambiyar, \& Ishak. (2020). Blended Learning: A 21st Century Learning Model At College. International Journal Of Multi Science, 1(8), 50-65.

Fajra, M., Suparno, Sukardi, Ambiyar, Novalinda, R. (2020). Project-Based Learning Innovation To Improve The Suitability Of Productive Competencies In Vocational 
School With The Needs Of The World Of Work. International Journal Of Multi Science, $1(8), 1-11$

Gohae, A. (2020). Pengalaman Magang, Minat Kerja dan Pengaruhya terhadap Kesiapan Kerja Mahasiswa Akuntanssi. JIMEA: Jurnal Ilmiah MEA, 4(3); 1954-1964.

Mallisza, D., Ambiyar, A., Dakhi, O., Verawardina, U., \& Siregar, M. (2021). design of acceptance information system of new students of national flight vocational high school. International Journal Of Multi Science, 1(10), 9-21.

Sarumaha, R., Harefa, D., \& Zagoto, M.M. (2018). Upaya Meningkatkan Kemampuan Pemahaman Konsep geometri Transformasi Refleksi Siswa Kelas XII-IPA-B SMA Kampus Telukdalam Melalui Model Pembelajaran Discovery learning Berbantuan Media Kertas Milimeter. Jurnal Education and development, Vol.6 No.1, 90-96, Institut Pendidikan Tapanuli Selatan, Padangsidimpuan. https://doi.org/10.37081/ed.v6i1.668

Sugianto, A., \& Suyitno, S. (2018). Pengaruh Kegiatan Praktek Kerja Industri Terhadap Kesiapan Kerja Di Sekolah Menengah Kejuruan Negeri 8 Purworejo. Auto Tech: Jurnal Pendidikan Teknik Otomotif Universitas Muhammadiyah Purworejo, 12(01). http://ejournal.umpwr.ac.id/index.php/autotext/article/view/4863/4467

Timor, A. R., Ambiyar, A., Dakhi, O., Verawardina, U., \& Zagoto, M. M. (2020). Effectiveness of problem-based model learning on learning outcomes and student learning motivation in basic electronic subjects. International journal of multi science, 1(10), 1-8

Zagoto, Maria M. (2018). Pengembangan Perangkat Pembelajaran Matematika Berbasis Realistic Mathematic Educations Untuk Siswa Kelas V Sekolah Dasar, Jurnal Education And Development, vol. 3, no. 1, p. 53, Feb. 2018. https://doi.org/10.37081/ed.v3i1.139

Zagoto, Maria M., Nevi Yarni \& Dakhi, O (2019). Perbedaan Individu dari Gaya Belajarnya Serta Implikasinya Dalam Pembelajaran. Jurnal Review Pendidikan dan Pengajaran, 2(2), 259-265.

Zagoto, Maria M. \& Dakhi, O (2018). Pengembangan Perangkat Pembelajaran Matematika Peminatan Berbasis Pendekatan Saintifik Untuk Siswa Kelas XI Sekolah Menengah Atas. Jurnal Review Pendidikan dan Pengajaran, 1(1), 157-170.

Zebua, Y. (2020). Media powerpoint berbasis video terhadap hasil belajar materi keselamatan dan kesehatan kerja (k3) pada mahasiswa pendidikan teknik bangunan. JRPP, 3(2), 469475 .

Zebua, Y. (2018). Penerapan model pembelajaran kooperatif tipe jigsaw dalam meningkatkan aktivitas dan hasil belajar siswa. Didaktik, 12(1), 2100-2111. 